Article

\title{
Being a Disabled Patient: Negotiating the Social Practices of Hospitals in England
}

\author{
Stuart Read *, Val Williams, Pauline Heslop, Victoria Mason-Angelow and Caroline Miles \\ Norah Fry Centre for Disability Studies, University of Bristol, Bristol, BS8 1TZ, UK; E-Mails: stuart.read@bristol.ac.uk (S.R.), \\ val.williams@bristol.ac.uk (V.W.), pauline.heslop@bristol.ac.uk (P.H.), victoria.mason-angelow@ndti.org.uk (V.M.-A.), \\ caroline.miles@bristol.ac.uk (C.M.)
}

* Corresponding author

Submitted: 14 December 2017 | Accepted: 27 February 2018 | Published: 17 May 2018

\begin{abstract}
Accessing hospital care and being a patient is a highly individualised process, but it is also dependent on the culture and practices of the hospital and the staff who run it. Each hospital usually has a standard way of 'doing things', and a lack of flexibility in this may mean that there are challenges in effectively responding to the needs of disabled people who require 'reasonably adjusted' care. Based on qualitative stories told by disabled people accessing hospital services in England, this article describes how hospital practices have the potential to shape a person's health care experiences. This article uses insights from social practice theories to argue that in order to address the potential problems of 'misfitting' that disabled people can experience, we first need to understand and challenge the embedded hospital practices that can continue to disadvantage disabled people.
\end{abstract}

\section{Keywords}

disability identification; disabled people; hospital; patient care; social practices

\section{Issue}

This article is part of the issue "Global Perspectives on Disability", edited by Shaun Grech (The Critical Institute, Malta) and Karen Soldatic (Western Sydney University, Australia).

(C) 2018 by the authors; licensee Cogitatio (Lisbon, Portugal). This article is licensed under a Creative Commons Attribution 4.0 International License (CC BY).

\section{Introduction}

We start with a seemingly simple problem, that of ensuring that disabled people who need hospital care in the UK receive fair and equal treatment. In the UK, the Equality Act 2010 imposes duties on organisations and service providers to ensure that disabled people are not discriminated against or treated less favourably than non-disabled people (Equality Act, 2010). For example, within the context of health care, the Equality Act 2010 provides disabled people with protections against being denied access to services, or receiving poor care, because of their disability. One protection is that health care providers must make changes or 'reasonable adjustments' to their existing practices to ensure that disabled people do not experience 'substantial' disadvantage. The Act provides an 'anticipatory' duty, for example by ensuring that the general environment is accessible to the range of people likely to need hospital care, with wheelchair accessible buildings and clear signage. In addition, there is a requirement to respond to the needs of individual disabled people, by, for example, changing the timing or length of an appointment, or ensuring that a family member can be involved in a disabled patient's care (Equality \& Human Rights Commission, 2015; MacArthur et al., 2015). Despite the legal framework of the Equality Act 2010, however, it is known that there remain significant inequities for disabled people throughout the UK health care system, including issues with transport, waiting lists, and additional health care cost implications (Sakellariou \& Rotarou, 2017; TuffreyWijne et al., 2014), and delays in diagnosis and treatment, such as for people with intellectual disabilities (Heslop et al., 2013). 
In this article we are interested in how hospital practices, and adjustments to those practices, are experienced by disabled people, at the embodied level of their physical and emotional experience. As became evident from our research, disability-related needs were often invisible or, notwithstanding the legal protections in place, ignored within the hospital system, and thus a major issue for disabled patients was the need to repeatedly advocate for themselves and explain their needs to staff. It is not always easy to know who counts as disabled, and the act of declaring or disclosing a disability is tightly bound up with the experience of being a patient in a hospital. We shall therefore provide next a brief overview of how the definition and meaning of disability can be shaped by cultural and systemic factors, before turning to an explanation of the social practice theories on which this article is based.

Although disability theorists are widely united in opposing a deficit model of disability (Oliver, 2013; Thomas, 2004), the turn towards a social model of disability is not always sufficient, given that disability is a fluid, contextrelated concept. Disability 'identification' is often problematic, and fraught with conflicting narratives, including those of disabled people themselves. Despite positive affirmations of disability pride (Swain \& Cameron, 1999), the identity of 'being disabled' is far from straightforward. Rejection of the disability identity is common, with many people with specific impairments refusing to see themselves as disabled (Watson, 2002). We explore identity in this article as an ongoing 'becoming' rather than as a one-off event. Disabled people themselves have foregrounded the interrelations between impairment effects and disability, which result in limitations, pain or difficulties, irrespective of the outer social world (Crow, 1996; Shakespeare, 2006). Further, the identity of 'being disabled' is closely dependent on social class, circumstance and on legal protections (see Williams, Swift, \& Mason, 2015). Those protections afforded by the Equality Act 2010 raise particularly problematic issues for identification, since an individual is only protected against 'discrimination arising from a disability' (section 15) if the organisation knew or could reasonably have been expected to know that they had a disability (section 15, subsection 2 ).

In this article, our aim is to apply social practice theoretical approaches, in order to better understand the disabling situations created by hospitals. The turn towards social practices (Reckwitz, 2002; Shove, Pantzar, \& Watson, 2012) directs the attention of social scientists towards the material, interconnected and 'ordered' ways in which things get done in everyday life, including within hospitals (Blue \& Spurling, 2017). Practices in this sense are not just the activities of practitioners or health care workers, but are simply the human activities in which we all may engage, and a social practice approach helps us to appreciate in more detail how practices are constituted, and how they could evolve or be changed to become more enabling. Shove et al. (2012) argue that social practices are influenced by three interconnected sets of elements: materials, competence and meaning. Materials are the tangible components that are implicated within a social practice. Competence refers to people's capability or knowledge to engage in a social practice. Meaning is the understanding and value people have of a social practice (e.g., an awareness about what is acceptable in this context). All these features that come together to make up a particular social practice will have an influence on how people feel about themselves, how they give meaning to their experience, and ultimately on how they identify or include themselves within particular practices. For instance, Lamont-Robinson, Williams and Thompson (2018) have shown in a different context how objects may be significant in shaping people's decisions and actions within individual practices, which in turn are then 'continually shifting and re-developing' (Lamont-Robinson et al., 2018, p. 2). When someone enters an environment where things are done in ways that do not include their own needs or perspectives, then the material elements of that practice (in this case, maybe waiting rooms, complex written information, or medical equipment) combine with the human interactions in that environment, to create what is often a negative, disempowering and 'misfitting' experience. Robillard (1999) observes in detail the disabling effect of encounters in an intensive care unit for someone who cannot communicate because of paralysis, and using an ethnomethodological lens (Garfinkel, 1967), he shows how such encounters impact on his own emotions and identity as an academic.

These ideas have started to resonate for disability theorists interested in how disabled people interact with an environment that may not be suited to their bodies or needs (e.g., Abrams, 2016; Garland-Thomson, 2011; Titchkosky, 2008, 2011). Even when the environment is 'adapted' to be made more accessible (LamontRobinson et al., 2018), individual disabled people can experience their own impairments in both positive and negative ways. Thus, a social practice argument would suggest that the experiences of disabled people in hospital can be influenced by a myriad of factors, both internal and contextual.

Our focus in this article is therefore both on the practices themselves, but also on the emotional impact of those practices, revealed through the lens of individual disabled people's narratives. As Goodley, Liddiard and Runswick-Cole (2018) note, in their exploration of theories of affect, " $t$ ] he turn to affect is not simply about addressing a missing psycho-emotional dimension in social theory. Affect theory responds to the ways in which affects are mobilised by economic and cultural forces' (Goodley et al., 2018, p. 199). The meaning associated with one's own condition or disability is tightly bound up with the social experiences and material arrangements of a particular context (Titchkosky, 2011), such as a hospital where a disabled person may be a patient. Being disabled in hospital may therefore be a complicated process for many reasons, as it may shape, and be shaped by, dis- 
abled people's overall experience as a patient and how staff respond to them. For example, the very notion of a 'reasonable adjustment' in hospital care can be problematic if it singles out a disabled patient as non-normative or as a 'misfit' (Garland-Thomson, 2011).

This article was written in 2017-2018 at a time of huge pressure in the UK health care system, particularly within hospitals in England, with frequent media reports about the difficulties experienced by patients and hospital staff. That is why it is important to reflect here on the ways in which the ideas about social practices may help to identify low-cost solutions which are based on creative changes to existing practices. Social practices do not exist in a vacuum, but in general they are tightly interconnected (Blue \& Spurling, 2017), and understanding those connections can be a key to better practice for all. Disabled patients' needs may be specific and individual, but their solutions may well be of universal benefit.

Moving back specifically to the relationship between disability and hospital care, we start from the position that disabled people, like others in the population, have needs for health care services (Burns, 2017); however, they may have additional health care needs associated with their impairments. For instance, when compared to individuals without an impairment, disabled people are more likely to experience chronic pain and arthritis (Havercamp, Scandlin, \& Roth, 2004), and require more use of health care services (Allerton \& Emerson, 2012). People with intellectual disabilities are also more likely to have health comorbidities than others in the population, such as epilepsy (Cooper et al., 2015; Marriott \& Robertson, 2014). Therefore, it is necessary not just to know and record the health service needs of disabled people, but to also understand how social practices interconnect with, and shape their experience of accessing adjusted health care. In this article we will seek to explore further disabled people's accounts of accessing hospital care in England, and highlight how their experiences and feelings are affected, both by existing standard hospital practices and also by the personalised adjustments made for them.

\section{Overview of Study}

The study data on which this article draws comes from a wide programme of research which is co-produced with disabled people's organisations (Williams et al., 2018), seeking to understand and challenge disabling social situations from several different domains of life. For this study, we have been analysing provisions of reasonable adjustments within the National Health Service (NHS) in England. We have taken a mixed-methodology approach, incorporating data from a variety of sources, such as an audit, online surveys and interviews. In our study we are interested in looking at systems of care from a social practice perspective (Blue \& Spurling, 2017; Williams et al., 2018). We suggest that any hospital has a standard way of 'doing things', which can shape not just how hospital staff and patients interact with the service, but also disabled people's experience as patients. Therefore, this study sought to understand disabled people's experiences of how they interact with, and are affected by, existing hospital practices.

This article focuses solely on twenty-one qualitative interviews with disabled adults who volunteered to share their story of a recent hospital experience. All participants who took part did so on the basis that they already self-identified as disabled. We did not require our participants to discuss their impairments in the interviews, however, the experiences they shared indicated that they had personal experience of a range of impairments (e.g., sensory impairments, physical impairments, mental health conditions, and intellectual disabilities). The sample consisted of twelve women, and eight men, with the remaining interview completed by a husband and wife collaboratively who both identified as disabled. People were recruited from a broad range of locations across England. The semi-structured interviews from which data were gathered asked participants to describe the stages of their hospital visit in the style of a 'journey', starting from before they arrived, and finishing at when they left hospital. Each interview was completed with the disabled person at their own home $(n=14)$, or by telephone $(n=7)$, and lasted approximately one hour. Interviews were recorded and transcribed, anonymising all names and details. The study received ethical approval from the Faculty of Social Sciences and Law Committee for Research Ethics, University of Bristol.

\subsection{Analysis}

We first read all our interview transcripts multiple times, and coded our data using 'process coding' (Saldaña, 2015), which aims to highlight the actions and practices on which experiential accounts are based, such as the social practices that disabled people and health care staff 'do' within a hospital setting. The interviews were then analysed using thematic analysis (Braun \& Clarke, 2006), which involved collating recorded process codes of similar meanings, and relating these to each other. This in turn, led to the construction and shaping of larger cross-cutting themes describing broad hospital practices. Process codes and themes were modified as new ideas emerged from the interviews. The lead author self-identifies as disabled, and has significant personal experience of accessing UK health services. His lived experience was used to help understand and interpret the findings. Collaborative discussions with others in the team also took place to refine and confirm the reported themes.

In the forthcoming section we will organise our findings under four types of social practice which emerged from the data: 1) being alerted to disabled people and their needs; 2) getting to and from hospital; 3) accessing 'good' information; and 4) getting what disabled people 
came for (i.e., the purpose of their hospital visit). Substantial quotations are included, so that we can reflect on the detail of emotion, reaction and embodied experience expressed by disabled people who have been hospital patients.

\section{Findings}

\subsection{Being Alerted to Disabled People and Their Needs}

In order to explore the experiences of disabled people, we first need to understand the terminology used by hospitals about their systems to become aware of disabled people and their needs. The first is what we call here 'identification', which is where hospital staff recognise that a patient is disabled. To achieve this, disabled people could describe the issue they face, naming it as a particular impairment, and subsequently ask for support, or this could also be accomplished on their behalf by a health professional or a family member or carer (Tuffrey-Wijne et al., 2013). The second is 'flagging', which involves formally marking patient records in order to alert hospital staff to a patient's disability, such as by adding a 'flag' or some other form of notification to patient records or notes; or having the patient carry a specific document describing their personalised information (Tuffrey-Wijne et al., 2013). While identification can take place without flagging, flagging cannot take place without prior identification that the person is disabled. Collectively then, the many ways of being alerted to the needs of disabled people expose a number of hospital social practices that shape how an individual patient engages with the service, and participants in this study did not necessarily experience these processes in the same way as the professional logic, nor the hospital's duties under the Equality Act 2010, would imply.

When considering the reasonable adjustments needed by an individual patient, that person must first be identified as disabled, which may be a daunting process in and of itself. One woman explained that while she welcomed her personal needs being identified, she felt that other disabled people might have reservations in identifying as disabled within the health care environment.

(9) Well, it's pretty obvious I am disabled, you know....But...it does need some flagging up. Certainly unseen disabilities....But I suppose, yeah, there are some that have got things wrong that they don't want people to know.

This individual's example also highlights that hospital staff may be more able to recognise people with visible impairments, who self-identify, when compared to people with less visible impairments. Therefore, the typical identification procedures of hospitals may also influence disabled people's decisions to identify, since deciding to tell someone about a disability is made far more straightforward if that knowledge is shared from the outset.
Regardless of how a disabled person's needs are identified, in order for an individual's care needs to be met effectively, practices have to incorporate and respond to these needs. If hospitals do not have appropriate practices in place, this makes the process of identifying for disabled people potentially meaningless. Participants discussed how at times, hospitals may not be effective at accommodating disabled people's needs, even following identification. For example, one man described:

(16) So, my biggest complaint is that the fact that I'm disabled has no significance whatsoever in the system. Whatsoever. They are not really bothered about you being disabled. You're just another patient, aren't you?

A similar story was reported for methods of formal flagging systems, where participants discussed how their disability and needs for adjusted care may not be routinely recorded, or that hospital staff may not adapt their practice to accommodate this flag. For example, one woman described:

(11) Some people seem to have a record of it when I go in, and other people don't. Yeah, so it seems as if sometimes...people don't notice that it's there, either, when it's written.

\subsection{Getting to and from Hospital}

Hospital practices go beyond simply identifying the reasonable adjustment needs of disabled people-they shape whether and how these reasonable adjustments are enacted. Take for example, getting to or from the hospital doorway. This of course involves a journey for everyone, generally using some form of motorised transport, such as an ambulance or a relative with a car. The act of getting to hospital involves numerous connected social practices, such as planning the journey, using a particular method of transport, and parking. Each of these social practices, and the people that are involved within them (e.g., disabled people and staff), are connected, and must work together effectively to ensure a positive experience. A common experience for our participants was that accessing hospital transport was problematic for several reasons, such as the service not being wheelchair accessible, or that journeys often ran to tight schedules, or took a long route in order to pick up multiple passengers. One woman commented:

(8) If you go with a friend, you can say, 'Can we go really early, to have time to prepare myself when I'm actually there...not running in at the last minute?' But with the hospital cars provided, they do cut it quite fine. And that was a problem to me.

Thus, if participants decided to use hospital transport, in order to ensure that their individual needs were met, 
they relied heavily on the sensitivity and knowledge of staff involved, which was not always evident. One woman described:

(6) I know now, but I didn't know at the time, when I started first getting transport, I just thought, Oh, I'm safe. I've got an ambulance driver. And I'm sure these people that have had heart transplants and lung transplants felt the same. But they [ambulance driver] are not. All they are is they've had first aid.

The practices involved in getting to hospital are a key example of how the interconnections between different players are vital to a patient's experience of fitting or misfitting into the hospital system. This was also true for disabled people making their own journeys to hospital independently, with one participant noting the expectation that she would have to announce her arrival, while inconveniencing other drivers:

(3) One of the things that happens then is...there's a barrier to actually get into the car parks.... have a car which I load from the back with a ramp that goes down, and it fixes, because I drive from a power chair. So, I'm fixed in, and I'm not terribly tall. So, I can't actually reach to press the button to release the barrier. We've had a conversation about that with the [Trust]...[their] idea is that they should put a note on the barrier with a phone number, so that I would phone to let them know that I'm outside. That doesn't work really, because you're out of pocket anyway, for the phone call, and you cause a blockage for everybody behind.

\subsection{Accessing Good Information}

The point at which people accessing hospital care 'become' patients is potentially problematic as this can result in some conflicted feelings about a person's own identity and how they will be treated (Sokol, 2004). This is especially true for disabled people, and study participants expressed concerns about hospital processes for receiving and sharing information about their care. People wanted clear and understandable information and at times, reported that this was not forthcoming. They spoke of their need for adjusted information, and their struggles in obtaining this, with one participant highlighting that hospital staff may not necessarily understand how to provide accessible information for disabled patients: (4) “When you do get there...they don't know that they can do it in large print". This, in turn, may create feelings of disempowerment: (2) “I'm not the boss any more. I am kind of like a-I'm a nobody. Because I'm sat down here, and all this conversation's going over my head."

However, there was also a fear that one's disability could result in patronising treatment. One participant with a visual impairment pointed out that information she received from hospital staff may be unnecessarily over-simplified, explaining that: (5) "I've got a degree, and a postgraduate qualification, and a whole working life at senior level behind me. And it's offensive to be spoken down to." Another participant expressed concern at being seen as a difficult patient, because of a need for a specific format of information:

(12) The endocrinology departments...they send letters like so small print.... don't even ask large print anymore, because they, they already are not really helpful medically.... don't want to risk them not liking me....I don't want to be the difficult patient.

Entering a hospital for any patient is often associated with some anxiety, especially if one is being tested for a particular condition, or when the outcome of treatment is risky or unknown. However, this anxiety can be exacerbated for disabled patients who may need reasonable adjustments to how information is provided about their treatment. There were many examples from participants about how they felt they were not kept informed of their treatment, which at times caused anxiety. A common practice which our participants reflected on was that of sitting in a reception area, and waiting for their name to be called, or for their professional to come along. One man described feeling forgotten while waiting for a specialist, as his visual impairment meant that he experienced difficulty in seeing what was going on or how the appointment process was working:

(20) These appointments take two, three, even sometimes four, five hours, you know....So that's a shame, because while you're waiting...you're...thinking, did, did they [forget] you...so...from then it's like a big, big stress.

Such negative experiences can contribute to a sense of isolation reported by many of our participants. For example, another participant described:

(11) I mean there are lots of different kinds of situations where that could be the case for any disability, where, because of the adjustments you need, and they're not in place, you suddenly feel very isolated from what's going on. And on the day of an operation, or in any health situation, I think the last thing you want is to feel alone and isolated.

In this sense, effective communication was highly valued by participants. Adjusting practices to include time for personal communication may seem difficult to achieve, but much of this is about paying attention to the person. For example, one woman described: (7) "They [hospital staff] treated me alright. When I was an in-patient, and also before, the consultant was good. He was saying all the things that [were] going to happen." 


\subsection{Getting What You Came for}

The notion of making a 'reasonable adjustment' can imply a rather straightforward arrangement, whereby a practice that was previously inaccessible or difficult to access, is simply made accessible. However, our participants described some complex interactions between their own experiences of pain or fear, their disabilityrelated needs, and the actual procedure for which they had entered hospital. Some disabled people described how they felt they became 'objects', and thus their reasonable adjustment needs were ignored by health professionals. One participant with a physical impairment described how he was required by a medical professional to manually move himself on a hospital bed, and given the nature of his impairment, this was not something he was able to do independently. He described how his specific needs were therefore disregarded:

(15) She [health professional] said, 'Well he can walk. He can walk. He can walk there, can't he?' And I said, 'Well yeah, I can walk'. She said, 'Start getting undressed'...there was no sort of realising that I actually needed somebody in there.

The result of problematic hospital practices was, on occasions, that disabled people were made to feel embarrassed at being the cause of chaos or confusion, and this concern was exacerbated by the verbal comments of staff. For example, one participant who required use of a wheelchair to attend his hospital appointment, discussed the following experience:

(18) Once they'd got me onto the bed, then they had to move the wheelchair themselves, and with powered wheelchairs, you can disengage the motors and it acts like a manual wheelchair. But to try and tell someone how to disengage...plus I had a respiratory mask on. So, they can't understand you, and then they try to operate it by...the power stick. And of course, the wheelchair goes in opposite direction, it's banging against very expensive equipment, running over people's toes, they're making comments about, 'Oh, this wheelchair', you know, and you feel very much that it's your fault. That you've brought your wheelchair in, that you need.

Other participants spoke about how they had to go through hospital procedures that were not suited to their individual needs. For instance, one participant with a physical impairment described having to complete a lengthy assessment, and she became extremely distressed because of the discomfort this caused.

(6) I was expected to climb on this bike. As far as they were concerned, they had a job to do, and they had to get me on the bike first, and then inject me, and then tell me to be doing all this cycling. And it was too high;
I thought I was going to fall off all the time.

In addition, screens, monitors and other equipment and artefacts represent in some respects the mystique as well as expertise of the medical profession, and could result in the patient becoming side-lined by the practitioner. While this may be so for any patient, this aspect of hospital practices can be particularly problematic for a disabled patient. The above participant added the following example in relation to her hospital procedure:

(6) But the whole experience that particular day was, the chap that was doing the diagnostic test was so [enthralled] with what he was doing, looking at the heart and all this on the telly, it was almost as if he'd just blotted me out. Because I was crying on the table for ages, and he was just carrying on. And he was teaching another student. So, he was really teaching her, so he wasn't really able to deal with me.

Because of her evident distress, she was told she did not have to undergo the next level of tests, even though she was aware that others were having the full procedure, and so she left hospital not knowing whether the tests had been fully completed and whether accurate results would be recorded. Fear and panic associated with disability needs can thus exacerbate, and be exacerbated by, the feelings of anxiety about the procedure itself and its results.

Nevertheless, episodes of care were not always problematic. Some participants reported how they valued being viewed and treated by their health provider in a more 'human' way. For example, one woman noted how her health care provider understood that being a disabled patient was one aspect of her multiple identity roles, which in turn, allowed her health care to be individualised to meet her specific needs:

(10) Now the doctor in charge there was a fantastic lady...she spontaneously said, 'Would you like your daughter to come in and meet with me? Would you like her to have a tour?' And I was like, 'No, she's fine, we've dealt with it all'. But I thought that was really intuitive, and that was really meeting the needs. Because...if I had...been worried about my daughter....I wouldn't have been able to cope....I wouldn't have been able to make the most of my treatment...so I think you're not just a patient, you're also a mother, a father, an employee, a neighbour. You know, you have other aspects to your life, apart from the fact that you've got that disability....And I thought that was really good, that she met that need by responding to that human need, or that need as a mother.

\section{Discussion}

The findings reported in this article represent potentially difficult experiences for disabled patients who need 
to request adjustments to meet their individual needs, but misfit within a relatively intractable system not designed to fit individual circumstances. These experiences appear to breach both the letter and the spirit of the Equality Act 2010. The extent to which knowledge and implementation of Equality Act duties are embedded within social practices in health care settings requires further research.

The image of the disabled woman at a car park barrier, unable to move forward, is a symbol maybe for how several participants felt about their hospital experience. It is important to note, however, that our account in this article cannot be generalised to all disabled people, but should be read as a qualitative enquiry into the connections between a set of practices and the personal experiences of being a patient in hospital. What we have outlined in our analysis is how each stage of the hospital journey includes practices which can be disabling - or can become more enabling. Problems arise when things are designed in such a way that disabled people are forced to confront their difference, and to make that difference visible to others. As we have seen, this can become a problem in itself, resulting in disabled patients feeling guilty, anxious or just frustrated. Further, the interaction between being a patient and being a disabled person can be problematic, when people feel they are perceived as difficult. Being a 'good patient' (Sokol, 2004) is associated with passivity and acceptance of the expertise of the medical profession. It seems then, that disabled people may have to navigate a difficult balance between maintaining the positive integrity of their role as a disabled patient, while also responding to disabling social practices that may challenge that integrity, in order to obtain good support. All this requires considerable emotional work, at a point when arguably one's focus should be on one's own health. The Equality Act 2010 legislation, intended to mitigate or remove disabling practices seems, on the face of these personal accounts, to have had little impact on day-to-day experiences.

How then can social practice theories allow us to analyse and shift the practices in hospital care? Blue and Spurling (2017) take a historical approach to the analysis of change in the interconnected practices within hospitals, arguing that there is a 'connective tissue' which includes time management and materiality, binding practices together in a hospital. For instance, a patient's records and indeed their disability-related needs, may be one form of materiality which is shared between different departments and professionals in a system. While that interconnection of material elements in a practice may be important, this article has also shown how values and meanings are contained in the interactions with disabled people in hospital. In a negative sense, that value system can become apparent when a patient is made to feel that their individual needs are secondary to the needs of the technology or the medical procedure. Robillard (1999), like some of our own participants, was often made to feel that he constituted the problem, and that he was positioned as powerless by the failures of communication which went on around him. Unfortunately, the very notion of a 'reasonable adjustment' can also have this effect, as we have seen in this article, since the disabled patient is made to feel different and problematic. Thus, a social practice approach might be relevant not just to the provision of reasonable adjustments themselves, but to an understanding of how such adjustments might be made routinely within a more fluid or patientcentred system while ensuring compliance with specific legal duties. In practical terms, what we are suggesting is that any institutionalised or professional practice can be open to change, that human rights legislation can and should make a difference to those practices, and that a positive way forward is to focus on understanding the experiences of disabled patients themselves.

\section{Acknowledgments}

This work was supported by a grant from the Economic and Social Research Council (ES/M008339/1): 'Tackling Disabling Practices: co-production and change'. We also wish to thank our advisory group of disabled people, who have helped us with shaping the study, and the materials we used.

\section{Conflicts of interest}

The authors report no conflicts of interest.

\section{References}

Abrams, T. (2016). Cartesian dualism and disabled phenomenology. Scandinavian Journal of Disability Research, 18(2), 118-128.

Allerton, L., \& Emerson, E. (2012). British adults with chronic health conditions or impairments face significant barriers to accessing health services. Public Health, 126(11), 920-927.

Blue, S., \& Spurling, N. (2017). Qualities of connective tissue in hospital life: How complexes of practices change. In A. Hui, T. Schatzki, \& E. Shove (Eds.), The nexus of practices: Connections, constellations, practitioners (pp. 24-37). Oxford: Routledge.

Braun, V., \& Clarke, V. (2006). Using thematic analysis in psychology. Qualitative Research in Psychology, 3(2), 77-101.

Burns, N. (2017). The human right to health: Exploring disability, migration and health. Disability \& Society, 32(10), 1463-1484.

Cooper, S.-A., McLean, G., Guthrie, B., McConnachie, A., Mercer, S., Sullivan, F., \& Morrison, J. (2015). Multiple physical and mental health comorbidity in adults with intellectual disabilities: Population-based crosssectional analysis. BMC Family Practice, 16(110). doi:10.1186/s12875-015-0329-3

Crow, L. (1996). Including all of our lives: Renewing the social model of disability. In C. Barnes \& G. Mercer 
(Eds.), Exploring the divide: Illness and disability (pp. 55-72). Leeds: The Disability Press.

Equality Act (2010). Equality Act 2010. London: The Stationery Office Limited.

Equality \& Human Rights Commission. (2015). Your rights to equality from healthcare and social care services. Equality Act 2010: Guidance for service users (Vol. 4). London: EHRC.

Garfinkel, H. (1967). Studies in ethnomethodology. Cambridge: Polity Press.

Garland-Thomson, R. (2011). Misfits: A feminist materialist disability concept. Hypatia, 26(3), 591-609.

Goodley, D., Liddiard, K., \& Runswick-Cole, K. (2018). Feeling disability: Theories of affect and critical disability studies. Disability \& Society, 33(2), 197-217.

Havercamp, S. M., Scandlin, D., \& Roth, M. (2004). Health disparities among adults with developmental disabilities, adults with other disabilities, and adults not reporting disability in North Carolina. Public Health Reports, 119(4), 418-426.

Heslop, P., Blair, P., Fleming, P., Hoghton, M., Marriott, A., \& Russ, L. (2013). Confidential inquiry into premature deaths of people with learning disabilities (CIPOLD): Final report. Retrieved from http://www. bris.ac.uk/media-library/sites/cipold/migrated/doc uments/fullfinalreport.pdf

Lamont-Robinson, C., Williams, V., \& Thompson, T. (2018). Pitching perspectives on disability: Voyage experiences of disabled sailors on tall-ships. Scandinavian Journal of Disability Research, 20(1), 102-110.

MacArthur, J., Brown, M., McKechanie, A., Mack, S., Hayes, M., \& Fletcher, J. (2015). Making reasonable and achievable adjustments: The contributions of learning disability liaison nurses in 'Getting it right' for people with learning disabilities receiving general hospitals care. Journal of Advanced Nursing, 71(7), 1552-1563.

Marriott, A., \& Robertson, J. (2014). Making reasonable adjustments to epilepsy services for people with learning disabilities. London: Public Health England.

Oliver, M. (2013). The social model of disability: Thirty years on. Disability \& Society, 28(7), 1024-1026.

Reckwitz, A. (2002). Toward a theory of social practices: A development in culturalist theorizing. European Journal of Social Theory, 5(2), 243-263.

Robillard, A. B. (1999). Meaning of a disability: The lived experience of paralysis. Philadelphia, PA: Temple University Press.

Sakellariou, D., \& Rotarou, E. S. (2017). Access to healthcare for men and women with disabilities in the
UK: Secondary analysis of cross-sectional data. BMJ Open, 7(8). doi:10.1136/bmjopen-2017-016614

Saldaña, J. (2015). The coding manual for qualitative researchers (3rd ed.). London: Sage.

Shakespeare, T. (2006). Disability rights and wrongs. London: Routledge.

Shove, E., Pantzar, M., \& Watson, M. (2012). The dynamics of social practice: Everyday life and how it changes. London: Sage Publications.

Sokol, D. K. (2004). How (not) to be a good patient. BMJ, 328(7437), 471.

Swain, J., \& Cameron, C. (1999). Unless otherwise stated: Discourses of labelling and identity in coming out. In M. Corker \& S. French (Eds.), Disability discourse (pp. 68-78). Buckingham: Open University Press.

Thomas, C. (2004). How is disability understood? An examination of sociological approaches. Disability \& Society, 19(6), 569-583.

Titchkosky, T. (2008). "To pee or not to pee?" Ordinary talk about extraordinary exclusions in a university environment. Canadian Journal of Sociology, 33(1), 37-60.

Titchkosky, T. (2011). The question of access: Disability, space, meaning. Toronto: University of Toronto Press.

Tuffrey-Wijne, I., Giatras, N., Goulding, L., Abraham, E., Fenwick, L., Edwards, C., \& Hollins, S. (2013). Identifying the factors affecting the implementation of strategies to promote a safer environment for patients with learning disabilities in NHS hospitals: A mixed-methods study. Health Services and Delivery Research, 1(13), 1-248.

Tuffrey-Wijne, I., Goulding, L., Giatras, N., Abraham, E., Gillard, S., White, S., .. . Hollins, S. (2014). The barriers to and enablers of providing reasonably adjusted health services to people with intellectual disabilities in acute hospitals: Evidence from a mixed-methods study. BMJ Open, 4(4). doi:10.1136/bmjopen-2013004606

Watson, N. (2002). Well, I know this is going to sound very strange to you, but I don't see myself as a disabled person: Identity and disability. Disability \& Society, 17(5), 509-527.

Williams, V., Swift, P., \& Mason, V. (2015). The blurred edges of intellectual disability. Disability \& Society, 30(5), 704-716.

Williams, V., Tarleton, B., Heslop, P., Porter, S., Sass, B., Blue, S., . . . Mason-Angelow, V. (2018). Understanding disabling barriers: A fruitful partnership between disability studies and social practices? Disability \& Society, 33(2), 157-174.

\section{About the Authors}

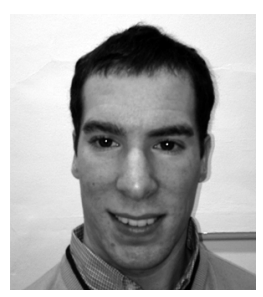

Stuart Read is a Senior Research Associate at the Norah Fry Centre for Disability Studies, University of Bristol, working on the strand of 'Getting Things Changed' relating to hospital services. He completed his PhD in Psychology in 2015. Stuart has particular interests in disability identity and identity presentation, as well as understanding how disabled people experience and navigate disabling social barriers in a number of different contexts. Stuart identifies as a disabled person. 


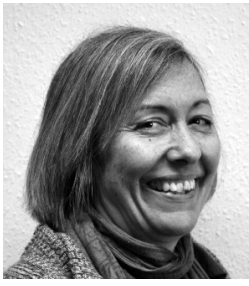

Val Williams is a Professor at Norah Fry Centre for Disability Studies, and has a background in Further Education and inclusion. She is chiefly interested in working with disabled people in 'inclusive research' designs, and also has an active engagement with methods to analyse social interaction. She leads the team conducting the research programme known as 'Getting Things Changed'.

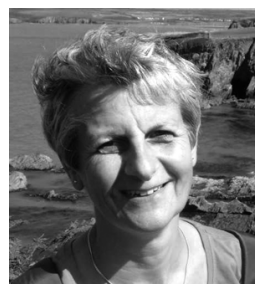

Pauline Heslop led the Confidential Inquiry into Premature Deaths of People with Learning Disabilities (CIPOLD) from 2010-2013 which identified potentially modifiable factors associated with premature deaths in people with learning disabilities. She is now the Programme Lead for the national Learning Disabilities Mortality Review (LeDeR) Programme, and leads the research on hospital services in 'Getting Things Changed'.

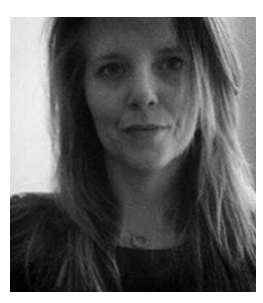

Victoria Mason-Angelow is a Research and Evaluation Consultant at NDTi, having recently joined the organisation from the Norah Fry Centre for Disability Studies (NFCDS) where she was a Research Associate. In her role at NFCDS, Victoria worked on a variety of studies relating to the lives of people with intellectual disabilities and those who identify as disabled within a UK Higher Education context. During her time at NFCDS Victoria also completed her PhD in Disability Studies, and conducted interviews in the 'Getting Things Changed' project.

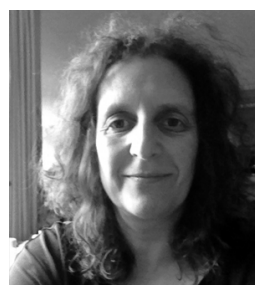

Caroline Miles is a Research Associate at the Norah Fry Centre for Disability Studies (NFCDS), and is also completing a School for Social Care Research (SSCR) Fellowship, 'The Legal Context of Social Care'. Caroline is a qualified solicitor with 13 years' experience in legal aid social welfare and community care law. Caroline initially joined NFCDS in 2015 as Research Associate for an adult care assessment research project, 'Values of Assessment', before moving to the 'Getting Things Changed' project. Caroline identifies as disabled and is a wheelchair user. 